\title{
COMPARISON OF INTRAVITREAL BEVACIZUMAB AND TRIAMCINOLONE ACETONIDE WITH INTRAVITREAL BEVACIZUMAB ALONE IN MACULAR EDEMA SECONDARY TO CENTRAL RETINAL VEIN OCCLUSION
}

\section{Usman Attique', Yousaf Jamal Mahsood ${ }^{\natural}$, Sanaullah Jan'}

\section{ABSTRACT}

OBJECTIVES: To compare the effect of intravitreal-bevacizumab (IVB) and intravitreal-triamcinolone (IVT) with IVB alone on visual acuity (VA) and central foveal thickness (CFT) in patients with macular edema (ME) secondary to central retinal vein occlusion (CRVO).

METHODS: This quasi-experimental study was conducted from June 2018 to December 2018 on patients with ME secondary to CRVO, admitted at Hayatabad Medical Complex, Peshawar, Pakistan. Out of thirty patients included in this study, fifteen were included in Group-A (received combination therapy IVT and IVB) and I5 in Group-B (received IVB alone). The subjects were followed up at $3^{\text {rd }}$ and $6^{\text {th }}$ month post-treatment and changes in VA (logMAR) and CFT were recorded at each visit. The comparative analyses of variables were carried out with-in the groups and between the groups.

RESULTS: Mean age of patients was $60.93 \pm 4.38$ years (group-A) and $60.73 \pm 3.67$ years (group-B). Mean VA at baseline $\& 6^{\text {th }}$ month was $0.87 \pm 0.09$ \& $0.32 \pm 0.06$ in group-A as compared to $0.88 \pm 0.10$ to $0.44 \pm 0.06$ LogMAR units in group-B respectively $(\mathrm{p}<0.00 \mathrm{I})$. Mean CFT at baseline \& 6th month was $673.67 \pm 38.33 \& 264.4 \pm 16.73$ in group-A as compared to $674.07 \pm 36.32$ \& $27 \mathrm{I} .0 \mathrm{I} \pm 20.14 \mathrm{im}$ in group-B respectively $(\mathrm{p}<0.00 \mathrm{I})$. There was no significant difference in CFT between the two groups at $3^{\text {rd }}$ month $(p=0.84)$ and $6^{\text {th }}$ month $(p<0.33)$ post-treatment, although it was statistically significant when compared within the groups.

CONCLUSION: Combined treatment is more effective than IVB alone in improving VA in CRVO related ME. However, the effect of combined treatment on CVT is not superior to IVB alone.

KEY WORDS: Central Retinal Vein Occlusion (MeSH); Bevacizumab (MeSH); Triamcinolone (MeSH); Intravitreal Injections (MeSH); Macular Edema (MeSH); Visual Acuity (MeSH).

THIS ARTICLE MAY BE CITED AS: Attique U, Mahsood YJ, Jan S. Comparison of intravitreal bevacizumab and triamcinolone acetonide with intravitreal bevacizumab alone in macular edema secondary to central retinal vein occlusion. Khyber Med Univ J 2021;13(1):15-9. DOI: https://doi.org/ 10.35845/kmuj.2021.21087.

\section{INTRODUCTION}

$\mathrm{R}^{\mathrm{e}}$ etinal Vein Occlusion (RVO) affects more than 16 million adults worldwide.' Vein occlusions are the second leading cause of decreased vision from retinal vascular disease, after diabetic retinopathy. The Central Retinal Vein Occlusion (CRVO) results from the obstruction to venous flow leading to congestion, hemorrhages, capillary nonperfusion, ischemia, and edema.' The identified risk factors are hypertension, diabetes mellitus, glaucoma, shorter axial length, age, and smoking. ${ }^{2}$ CRVO often presents with a sudden decrease in vision or with distortion, warped, or wavy vision, floaters, tiny dark spot in the field of vision the symptoms become worse over matters of hours and days. ${ }^{3}$ Clinically the CRVO is divided into impending CRVO, non-ischemic CRVO, and ischemic CRVO. ${ }^{4.5}$ Vascular endothelial growth factor (VEGF) produced
I: Department of Ophthalmology, Khyber Girls Medical College/Hayatabad Medical Complex, Peshawar, Pakistan

Cell \# +92-333-9102980

Email网: yousaf82@hotmail.com

Date Submitted: December 06, 2020

Date Revised: March 23, 2021

Date Accepted: March 24, 202I

due to retinal ischemia leads to loss of blood-retinal barrier resulting in macular edema (ME) and retinal neovascularization. ${ }^{6,7}$ Triamcinolone acetonide has shown efficacy in stabilizing the bloodretinal barrier by decreasing cell membrane permeability, inhibiting polymorphonuclear infiltration to injured tissues, blocking macrophage recruitment and phagocytosis, and downregulating inflammatory cytokines such as interleukin-5, 6, 8, tumor necrosis factor, and prostaglandins. ${ }^{8}$ Studies have also suggested the efficacy of corticosteroids in downregulating the receptors of vascular endothelial growth factor (VEGF). ${ }^{8}$ Bevacizumab acts by binding and inhibiting the receptors of VEGF on the surface of endothelial cells. This leads to a decrease in the action of VEGF which results in a decrease in angiogenesis and vascular permeability. 910 The diagnosis of CRVO is clinical and monitoring of disease is by visual acuity (VA) and central foveal thickness (CFT) by Optical Coherence Tomography (OCT). ${ }^{7}$ The treatment of non-ischemic CRVO with ME is intravitreal Anti-VEGF therapy or Ozurdex implant." Commonly used Anti-VEGF to treat ME due to CRVO are Bevacizumab, Ranibizumab, and Aflibercept. ${ }^{12}$ Bevacizumab is most commonly used in developing countries due to its low cost. The CRVO patient has been classified into a treatment responder and a lowresponder group based on VA and central retinal thickness (CRT) change. ${ }^{13}$

It is well known that intravitreal steroids and intravitreal Anti-VEGF can improve VA and CFT in ME due to CRVO. . $13^{0}$ However, there is limited knowledge on 


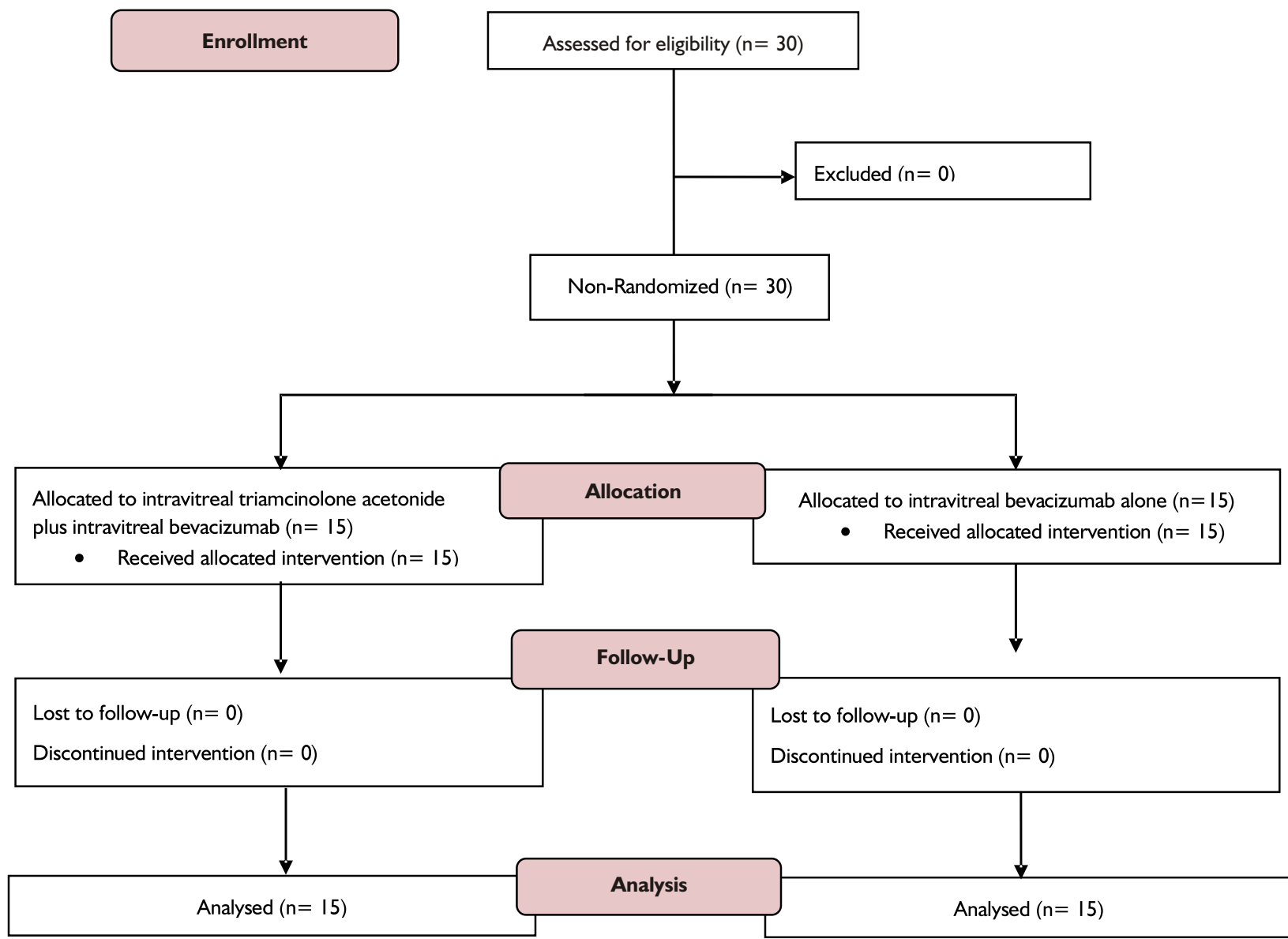

Figure I: Methodology flow chart

whether a combination of these two has better effects than intravitreal antiVEGF alone. ${ }^{14}$ This study was designed to know the effects of combined therapy of intravitreal bevacizumab ( $1.25 \mathrm{mg} /$ $0.05 \mathrm{ml}$ ) and triamcinolone acetonide $(2 \mathrm{mg} / 0.05 \mathrm{ml})$ injections in comparison to intravitreal bevacizumab (IVB) alone in the treatment of ME due to CRVO. This study will give us evidence of added beneficial effects (if any) of combination

TABLE I: BASELINE DEMOGRAPHICS OF THE STUDY POPULATION $(\mathbf{N}=30)$

\begin{tabular}{|c|c|c|c|c|}
\hline \multicolumn{2}{|c|}{ Parameters } & $\begin{array}{c}\text { Group A } \\
\text { (IVT+IVB) }\end{array}$ & $\begin{array}{c}\text { Group B } \\
\text { (IVB Alone) }\end{array}$ & \multirow{5}{*}{$\mathbf{P}$ - value $\psi$} \\
\hline \multirow{2}{*}{$\begin{array}{l}\text { Gender } \\
\text { distribution }\end{array}$} & Male $(n=17)$ & $10(33.33 \%)$ & $7(23.33 \%)$ & \\
\hline & Female $(n=13)$ & $5(16.67 \%)$ & $8(26.67 \%)$ & \\
\hline \multirow{2}{*}{$\begin{array}{l}\text { Treated } \\
\text { eye }\end{array}$} & Right $(n=17)$ & 9 & 8 & \\
\hline & Left $(n=13)$ & 6 & 7 & \\
\hline \multicolumn{2}{|c|}{ Age in years (SD) } & $60.93 \pm 4.38$ & $60.73 \pm 3.67$ & 0.89 \\
\hline \multicolumn{2}{|c|}{$\begin{array}{l}\text { VA in LogMAR at Baseline } \\
(\text { Mean } \pm S D)\end{array}$} & $0.87 \pm 0.09$ & $0.88 \pm 0.10$ & 0.86 \\
\hline \multicolumn{2}{|c|}{$\begin{array}{l}\text { CFT in microns at Baseline } \\
(\text { Mean } \pm S D)(u m)\end{array}$} & $673.67 \pm 38.33$ & $674.07 \pm 36.32$ & 0.98 \\
\hline
\end{tabular}

therapy in the management of $\mathrm{ME}$ secondary to CRVO and if found more effective then it will be used as treatment guidelines for treating such patients.

\section{METHODS}

The study was approved by the ethical review committee of Hayatabad Medical Complex, Peshawar, Pakistan and adhered to the tenets of the declaration of Helsinki (Ref. no. 094/HEC/PICO/ I8). It was a quasi-experimental study conducted at the Department of Ophthalmology, Hayatabad Medical Complex (HMC), Peshawar from June 2018 to December 2018. This trial was registered with https://clinicaltrials.gov (ClinicalTrials.gov Identifier: NCT048I 2 977). The sample size for this study was calculated by a two-sample comparison of percentages calculator in which postinjection percentages were used. The SCORE study had shown that 3-line visual acuity gain was 30 percent from the baseline while another study conducted in India had shown that 3-line gain of visual acuity in 85 percent of patient $^{15}$. For a 2-sided confidence level of $95 \%$ and power of $80 \%$, the total sample size of 30 subjects with 15 in each group was calculated by using an online calculator. The subjects were recruited from the out-patient department (OPD). The written informed consent was taken from all subjects. 
TABLE II: CHANGES IN VISUAL ACUITY \& CENTRAL FOVEAL THICKNESS FROM BASELINE TO $6{ }^{\text {TH }}$ MONTH POST TREATMENT (WITHIN THE GROUPS COMPARISON) ( $\mathbf{N}=30)$

\begin{tabular}{|c|c|c|c|c|}
\hline \multicolumn{2}{|c|}{ Parameters } & $\begin{array}{c}\text { At baseline } \\
(\text { Mean } \pm \text { SD) }\end{array}$ & $\begin{array}{c}\text { At }{ }^{\text {th }} \text { month } \\
\text { post-treatment } \\
(\text { Mean } \pm S D)\end{array}$ & P value \\
\hline $\begin{array}{c}\text { Visual Acuity } \\
\text { (LogMAR units) }\end{array}$ & Group A & $0.87 \pm 0.09$ & $0.32 \pm 0.06$ & $<0.001$ \\
\cline { 2 - 5 } & Group B & $0.88 \pm 0.10$ & $0.44 \pm 0.06$ & $<0.001$ \\
\hline $\begin{array}{c}\text { Central Foveal } \\
\text { Thickness }(\mu \mathrm{m})\end{array}$ & Group A & $673.67 \pm 38.33$ & $264.4 \pm 16.73$ & $<0.00 \mathrm{I}$ \\
\cline { 2 - 5 } & Group B & $674.07 \pm 36.32$ & $271.01 \pm 20.14$ & $<0.001$ \\
\hline
\end{tabular}

$n=$ Total number of participants, $S D=$ Standard deviation, $\varphi=$ Paired sample $t$-test was applied

Non-random sampling technique was used. Subjects were assigned to the treatment groups based on their presentation sequence; odd numbers were sent to Group $A$ and even numbers to Group B. The CONSORT 2010 flow diagram is shown in figure $I$. Subjects of either gender, age greater than or equal to 40 years, having ME secondary to CRVO, best-corrected visual acuity (BCVA) of less than or equal to 0.3 on Log MAR chart (Snellen equivalent of $6 / / 2$ ), CFT greater than or equal to 250 microns on Heidelberg Spectralis Spectral Domain Optical coherence tomography (SD-OCT) and clinical diagnosis of CRVO by consultant vitreo-retina were included in this study. Subjects excluded from the study were those who previously recei-ved laser treatment and/or intravitreal injection of any Anti-VEGF agent, having one eye, diagnosed case of glaucoma, family history of glaucoma, young patient, and anyone who has received any treatment for CRVO before presen-ting to us. The slit lamp biomicroscopic examination was performed and clinically diagnos is of the presence of ME due to CRVO were documented. For each subject baseline (BCVA) was recorded on the Log MAR visual acuity chart. Base-line SD-OCT was done to record CFT.

A single injection of triamcinolone acetonide (Kenacort-A $®$ ) [2mg/0.05ml] and intravitreal bevacizumab (Avastin ${ }^{\circledR}$ ) [1.25mg/0.05ml] was given at the start of the treatment whereas intravitreal bevacizumab $(1.25 \mathrm{mg} / 0.05 \mathrm{ml})$ was repeated monthly for 3 months. Group A received combination therapy of IVB $(\mathrm{l} .25 \mathrm{mg} / 0.05 \mathrm{ml})$ and IVT $(2 \mathrm{mg} / 0.05 \mathrm{ml})$ injection while Group B received IVB $(1.25 \mathrm{mg} / 0.05 \mathrm{ml})$ alone. All subjects were observed by a vitreo-retina consultant. The main outcome of the study was an improvement in visual acuity and CFT on SD-OCT from baseline to the sixth month. At each subsequent visit at 3,6 months post-injection, patient visual acuity (VA in Log-MAR), and central foveal thickness (on SD-OCT) were measured.

The data were analyzed by using SPSS version 24 . The post-injection visual acuity and central foveal thickness were used to calculate results and student ttest were applied on these two variables of Group A and Group B. The with-in the groups and between the groups' comparisons were done to check for any statistical difference between the outcome at baseline and follow-up. A pvalue of $=0.05$ was taken as significant.

\section{RESULTS}

Out of 30 patients, 17 (56.7\%) were males and 13 (43.3\%) were females. A total of 30 eyes were in included in this study, 15 in either group. Right eye was involved in $17(56.7 \%)$ cases and left eye in $13(43.3 \%)$ cases. Mean age of patients was $60.93 \pm 4.38$ years and $60.73 \pm 3.67$ years in group $A$ and group $B$ respectively. Table I shows the baseline demographics of our study population. At baseline, there was no significant difference in age, VA, and CFT between the two groups.

Table II represents with-in the group's comparison; in both groups, the mean VA and CFT improved significantly at 6th-month post-treatment from baseline $(p<0.00 \mathrm{I})$. When we analyzed the results between the groups, we found that VA significantly improved in Group $A$ in comparison to Group B at $3^{\text {rd }}$ month $(\mathrm{p}=0.0 \mathrm{I} 7)$ and $6^{\text {th }}$ month $(\mathrm{p}<0.00 \mathrm{I})$ posttreatment. But there was no significant difference in CFT between the two groups at $3^{\text {rd }}$ month $(p=0.84)$ and $6^{\text {th }}$ month $(\mathrm{p}<0.33)$ post-treatment, although it was statistically significant when compared within the groups (Table III).

\section{DISCUSSION}

Our study aimed to compare the outcome of combination treatment (IVT+IVB) with IVB alone on VA and CFT in ME due to CRVO. We found that combination therapy has better effects on visual acuity gain as compared to IVB alone. Comparing anatomical results of this study with SCORE and CRUISE trial, the mean improvement in CFT in CRUISE trial is of 435 micron from baseline ${ }^{16}$ with a mean improvement in SCORE trial of CFT is of 118 microns from baseline. ${ }^{17}$ In our study, mean improvement in Group A (combination group) 409.26 micron while Group B (bevacizumab alone group) shows an improvement of 403 microns from baseline CFT. When comparing functional outcomes, in the CRUISE trial $47 \%$ of patients had greater than 3 -line visual acuity gain from baseline, ${ }^{16}$ and in the SCORE trial is $30 \%$ of the patient has 3 -line visual acuity gain from

TABLE III: CHANGE IN VISUAL ACUITY \& CENTRAL FOVEAL THICKNESS FROM BASELINE TO $6^{\text {TH }}$ MONTH POST-TREATMENT (BETWEEN THE GROUPS COMPARISON) $(\mathbf{N}=30$ )

\begin{tabular}{|l|l|c|c|c|}
\hline \multicolumn{2}{|c|}{ Parameters } & Group A (Mean \pm SD) & Group B (Mean \pm SD) & P - value $\psi$ \\
\hline \multirow{2}{*}{$\begin{array}{l}\text { Visual Acuity } \\
(\text { LogMAR units) }\end{array}$} & At baseline & $0.87 \pm 0.09$ & $0.88 \pm 0.1$ & 0.86 \\
\cline { 2 - 5 } & At 3 ${ }^{\text {rd }}$ month post-treatment & $0.6 I \pm 0.1$ & $0.69 \pm 0.07$ & 0.017 \\
\cline { 2 - 5 } & At 6 ${ }^{\text {th }}$ month post-treatment & $0.32 \pm 0.07$ & $0.44 \pm 0.06$ & $<0.00 \mathrm{I}$ \\
\hline \multirow{2}{*}{$\begin{array}{l}\text { Central Foveal } \\
\text { Thickness }(\mu \mathrm{m})\end{array}$} & At baseline & $673.67 \pm 38.33$ & $674.07 \pm 36.32$ & 0.98 \\
\cline { 2 - 6 } & At 3 ${ }^{\text {rd }}$ month post-treatment & $412.47 \pm 22.16$ & $414.60 \pm 34.18$ & 0.84 \\
\cline { 2 - 6 } & At 6 ${ }^{\text {th }}$ month post-treatment & $264.4 \pm 16.73$ & $271.07 \pm 20.14$ & 0.33 \\
\hline
\end{tabular}

$\mathrm{n}=$ Total number of participants, $\mathrm{SD}=$ Standard deviation, $\Psi=$ Independent sample t-test was applied 
baseline. $^{17}$ In our study, $66 \%$ of the patient has visual acuity gain of 3 -line in group A (combination group) while in group B (bevacizumab alone group) $59 \%$ of the patient has visual acuity gain of 3-line. Chiquet $\mathrm{C}$, et al. randomized patients to receive anti-VEGFs and dexamethasone implants in patients with CRVO shows significant improvements in visual acuity in the DEX group with no difference in CFT. ${ }^{18}$ The GENEVA study also showed that injection of dexamethasone implant had favorable in improving visual acuity during 6 months. ${ }^{19}$ Sharareh B, et al. also show that adding dexamethasone implant to complete or partial responders of bevacizumab results in significant improvement in both CFT and VA. ${ }^{20}$ The OMAR study compared adding Ozurdex and triamcinolone acetonide to refectory cases of cystoid ME despite repeated bevacizumab therapy in central vein occlusion which shows that adding steroid significantly improved CFT. ${ }^{21}$ Results of the Tanzanite Study concluded that combination therapy of intravitreal aflibercept and suprachoroidal triamcinolone acetonide had shown improvement in both visual and anatomical outcomes in patient with RVO. ${ }^{22}$ There is a transient increase of IOP among 4 patients of group A (7.5\%) after injection, which was returned to baseline level with topical anti-glaucoma medication. It is difficult to compare this study to the results of randomized control trials because these trials had slightly different inclusion criteria and were designed differently, in the present study there was a limited number of patients, and the study was conducted in only one hospital.

\section{CONCLUSION}

Combined treatment is more effective than IVB alone in improving VA in CRVO related ME. However, the effect of combined treatment on CVT is not superior to IVB alone. However, these findings represent short term results with combine IVB and IVT for ME secondary to CRVO. The prolonged Anti-VEGF effect of combination therapy may help reduce the number of injections and provide a prompt and sustained decrease in ME. IVB and IVT may have a synergistic effect on minimizing the sequelae of visionthreatening ME secondary to central retinal vein occlusion. We recommend further trials with a largęr sample șize and multi-centered approach to further evaluate the combination therapy for ME secondary to CRVO.

\section{REFERENCE}

I. Fuller JJ. Retinal Vein Occlusions: Update on Diagnostic and Therapeutic Advances. Focal Points 2007.

2. Pichi F, Hsu J, Lim JI, Tripathy K, Gill MK, Shah VA. Central Retinal Vein Occlusion. EyeWiki 2019. [Accessed on: December 05, 2020]. Available from URL: https://eyewiki.aao.org/ Central_Retinal_Vein_Occlusion.

3. Gregori NZ. What Is Central Retinal Vein Occlusion (CRVO)? American Academy of Ophthalmology. [Accessed on: December 05, 2020]. Available from URL: https://www. aao.org/eye-health/diseases/whatis-central-retinal-vein-occlusion.

4. Kooragayal LM. Central Retinal Vein Occlusion (CRVO). Medscape 2019 [Accessed on: December 05, 2020]. Available from URL: https://emedicine.medscape.com/a rticle/I 223746-overview.

5. Yoshizawa C, Saito W, Kase M, Ishida S. Clinical features of central retinal vein occlusion with inflammatory etiology. Asia Pac J Ophthalmol (Phila) 2012 Sep I;I(5):270-6. DOI: 10.1097/APO. Ob0I3e3I8266de04.

6. Lazic R, Boras I, Vlasc M, Gabric N, Tomic Z. Anti-VEGF in treatment of central retinal vein occlusion. Coll Antropol 2010 Apr 34:Suppl 2:6972.

7. Rhoades W, Dickson D, Nguyen QD, Do DV. Management of macular edema due to central retinal vein occlusionthe role of aflibercept. Taiwan J Ophthalmol 2017 Apr;7(2):70-6. DOI: 10.4103/tjo.tjo_9_17.

8. Mehta $\mathrm{H}$, Hennings $\mathrm{C}$, Gillies $M C$, Nguyen V, Campain A, Fraser-Bell S. Anti-vascular endothelial growth factor combined with intravitreal steroids for diabetic macular oedema. Cochrane Database Sys Rev 2018 April 18;4(4):CD0I I599. DOI: I0.1002/|465 I858.CD $011599 . p u b 2$.

9. Feldman B, Lim J, Tripathy K, Kim L, Karth P, Shah V. Bevacizumab. EyeWiki 2019. [Accessed on: December 05, 2020]. Available from URL: https://eyewiki.aao.org/ Bevacizumab.

10. Demir M, Dirim B, Acar Z, Sendul Y, Oba E. Comparison of the effects of intravitreal bevacizumab and triamcinolone acetonide in the treatment of macular edema secondary to central retinal vein occlusion. Indian J Ophthalmol 2014 Mar;62(3):279-83. DOI: 10.4I03/ 030I-4738.105769.

II. Mayer WJ, Wolf A, Kernt M, Kook D, Kampik A, Ulbig M, et al. Twelvemonth experience with Ozurdex for the treatment of macular edema associated with retinal vein occlusion. Eye 2013 Jul;27(7):8I6-22. DOI: 10.1038/eye. 2013.79 .

12. The Royal college of Ophthalmologist. Retinal Vein Occlusion (RVO) Guidelines, 18 Stephenson Way, London. The Royal college of Ophthalmologist. [Accessed on: December 05, 2020]. Available from URL: https://www.rcophth. ac.uk/wp-content/uploads/20 I5/ 07/Retinal-Vein-Occlusion-RVOGuidelines-July-20I5.

13. Brown DM, Campochiaro PA, Singh RP, Z Li, S Gray, Saroj N, et al. Ranibizumab for macular edema following central retinal vein occlusion: six-month primary end point results of a phase III study. Ophthalmology 2010 Jun; II7(6): I 124-33. DOI: 10.1016/j.ophtha. 2010.02 .022 .

14. Garweg G. Justus, Zandi S. Retinal vein occlusion and the use of a dexamethasone intravitreal implant (Ozurdex ${ }^{\circledR}$ ) in its treatment. Graefes Arch Clin Exp Ophthalmol 2016;254:1257x65. DOI: 10.1007/ s004|7-016-3350-x.

I5. Ali IR, Kapoor GK, Khan NA, Gibran KS. Efficacy of combined intravitreal bevacizumab and triamcinolone for 
branch retinal vein occlusion. Indian J Ophthalmol 2014 Apr;62(4):3969. DOI: $10.4103 / 0301-4738$. 120227.

16. Brown DM, Campochiaro PA, Singh RP, Li Z, Gray S, Saroj N, et al. Ranibizumab for macular edema following central retinal vein occlusion: Six-month primary end point results of a phase III study. Ophthalmology 2010; II7:1 I2 433.el.

17. Kooragayala ML. Central Retinal Vein Occlusion (CRVO). [Internet]. New York: Medscape; [Accessed on: December 05, 2020]. Available from URL: https://emedicine. medscape.com/article/I 223746 treatment\# d5.

18. Chiquet C, Dupuy C, Bron AM, Aptel F, Straub M, Isacio R, et al.
Intravitreal dexamethasone implant versus anti-VEGF injection for treatment-naïve patients with retinal vein occlusion and macular edema: a 12-month follow-up study. Graefes Arch Clin Exp Ophthalmol 2015 Dec;253(I2): 2095-102. DOI: 10.1007/s004I70I5-2947-9.

19. Haller JA, Bandello F, Belfort Jr R, Blumenkranz MS, Gillies M, Heier J, et al. Dexamethasone intravitreal implant in patients with macular edema related to branch or central retinal vein occlusion twelve-month study results. Ophthalmology $201 \mathrm{I}$; I I8(I2):2453-60. DOI: 10.1016/ j.ophtha.20I I.05.014.

20. Sharareh B, Gallemore R, Taban M, Onishi S, Wallsh J. Recalcitrant macular edema after intravitreal bevacizumab is responsive to an intravitreal dexamethasone implant in retinal vein occlusion. Retina 2013 Jun I;33(6): I227-3I. DOI: I0.1097/ IAE.0b0|3e3I827c53a0.

21. Ozkok A, Saleh OA, Sigford DK, Heroman JW, Schaal S. THE OMAR STUDY: comparison of ozurdex and triamcinolone acetonide for refractory cystoid macular edema in retinal vein occlusion. Retina 2015 Jul I;35(7): I393-400. DOI: I0.1097/IAE.0000000000000475.

22. Campochiaro PA, Wykoff CC, Brown DM, Boyer DS, Barakat M, Taraborelli D, et al. Suprachoroidal triamcinolone acetonide for retinal vein occlusion: results of the Tanzanite Study. Ophthalmol Retina 2018 Apr I;2(4):320-8. DOI: 10.1016/j.oret.2017.07.013.

\section{AUTHOR'S CONTRIBUTION}

Following authors have made substantial contributions to the manuscript as under:

UA: Conception and study design, acquisition of data, drafting the manuscript, critical review, approval of final version to be published

YJM: Acquisition of data, drafting the manuscript, critical review, approval of final version to be published

SJ: Acquisition, analysis and interpretation of data, drafting the manuscript, approval of final version to be published

Authors agree to be accountable for all aspects of the work in ensuring that questions related to the accuracy or integrity of any part of the work are appropriately investigated and resolved.

\section{CONFLICT OF INTEREST \\ Authors declared no conflict of interest \\ GRANT SUPPORT AND FINANCIAL DISCLOSURE \\ Authors have declared no specific grant for this research from any funding agency in the public, commercial or not-for-profit sectors}

\section{DATA SHARING STATEMENT}

The data that support the findings of this study are available on request from the corresponding author. The data are not publicly available due to privacy or ethical restrictions.

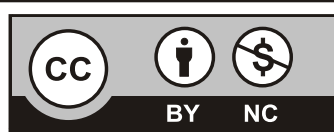

This is an Open Access article distributed under the terms of the Creative Commons Attribution-Non Commercial 2.0 Generic License.
KMUJ web address: www.kmuj.kmu.edu.pk

Email address: kmuj@kmu.edu.pk 